\title{
Perceptions towards Government Communication Strategies on COVID-19 Vaccination in Kenya
}

\author{
Daniel Robert Aswani \\ Daystar University \\ School of Strategic \& Organizational Communication, Daystar University \\ Nairobi, Kenya \\ Email: daswani [AT] daystar.ac.ke
}

\begin{abstract}
Kenya, like most countries in the world, continues to battle with the effects of the novel coronavirus (nCoV) popularly known as COVID-19. The rise in infections cannot be compared with a paltry $3 \%$ of the population that is fully vaccinated - a concern that puts the blame squarely on the way government has communicated on vaccine uptake. While there is an appreciation of constraining factors such as vaccine nationality 'wars', it is disturbing that where vaccines are availed, there remains anecdotal evidence on what spurs the hesitancy to take up vaccine in Kenya. This study sought to establish what drives the hesitancy in vaccine uptake by exploring the perceptions of COVID-19 survivors towards the communication strategies utilized by government to urge Kenyans to get vaccinated. The social influence theory provided a lens for understanding this phenomenon. Government communication strategies are competing with many voices that either deny the form of existence of the virus and hence refute the place of vaccines, or speak of the inefficiency of the vaccine, or create conspiracies around the use of vaccines. Good communication strategies seem to be the missing link in spurring the take up of COVID-19 vaccines and pushing the population to herd immunity. Only then, can the country encourage socio-economic development. This study answered research questions that explore problems, prospects, and perspectives that COVID-19 survivors (n=10) had towards the government communication strategies. The study took a phenomenological approach utilizing lived experiences of the survivors $(5$ now fully vaccinated and 5 are yet vaccinated). Explicated data was presented in themes. Participants noted use of different government communication strategies such as publicized vaccination of senior government officials; use of influencers; and use of media briefings. Based on findings and personal reflections, government communication strategies used by the government were reactive, pompous (or ignorant), and/or contradictory.
\end{abstract}

Keywords--- Government communication, Communication strategies, COVID-19, and COVID-19 vaccines

\section{INTRODUCTION}

The world's situation has been complicated thanks to COVID-19. The serendipitous gloom experienced by many countries turned hopeful when several COVID-19 vaccines were approved. The challenge of securing a better world in the face of the pandemic highly depends on the level of herd immunity in the different populations of the world. To gain high immunity, countries need to push the agenda of take up of COVID-19 vaccines - factor that is currently impeded by high levels of hesitancy. Vaccine uptake hesitance has been driven by many unanswered questions, unaddressed fears, and anxieties surrounding the vaccines. The greatest impediment around this pandemic seems infodemic. Since government communication exists to serve the citizenry by passing messages that would enable citizens to make informed choices and decisions, the spotlight on communication strategies used by government cannot be wished away. The situation is further compounded by the fact that governments world over, have been indicted for being slow and ineffective in the way they have managed the novel coronavirus (nCoV) popularly known as COVID-19, yet most governments had prior information about the virus (Dalzell, 2020).

\subsection{A Brief Background of the Study}

COVID-19 (SAC-COV-2 virus) continues to disrupt the socio-political and economic environment in many countries. There is need to stop, if not, manage the COVID-19 nightmarish effects. High COVID-19 vaccine uptakes will reduce infections and the resultant deaths. Further, a considerable population having received vaccines leads to herd immunity. Governments have a duty to balance the prevailing circumstances caused by COVID-19 and a desirable socio-economical future. Knowing the solution lies in mass vaccinations, one wonders how hesitancy in taking vaccines would be handled. While the Kenya government may be listed among the countries that did not take quick and decisive inceptual steps such 
as lock-down, the effects of COVID-19 cannot be gainsaid. On 31 August 2021, the Ministry of Health gave its 523 ${ }^{\text {rd }}$ briefing in which the total COVID 19 related deaths were put at 4,726 (Ministry of Health Kenya, 2021). The infection rates as at the same date show infection rates of $12.6 \%$.

Attempts to contain the contagious virus have taken the traditional methods of social (and/or physical) distancing, washing of hands, and masking up among many other methods. Such efforts in Kenya, continue to face the challenge mounted by political leaders who engage in super spreader events to the exclusion or imagination that COVID-19 is subject to political advertisement and aggrandizement. This political mischief has been fought by governments world over (Hyland-wood, Gardner, Leask \& Ecker, 2021).

By 31 August 2021, Kenya had received 2.3 million doses of vaccines and only 738, 339 Kenyans have been fully vaccinated (about 2.95\%). The initial target of the government was meant to mop up 3,133, 674 Kenyans drawn from health workers, security officers, teachers, and all above 58 years. The results from these groups are worrying. The uptake from health workers stands at $60.1 \%$; teachers have a $32.9 \%$ uptake; while those above 58 years, the uptake is at $8.7 \%$ (Ministry of Health Kenya, 2021). This statistical situation spells doom to the 27,246,033 adult population much as government targets to vaccinate about 10 million people by December 2021.

The uptake of available COVID-19 vaccine is hampered by fear and the spread of unverified rumors. As such, policymakers and implementors have one route out, namely managing communication well so that more people can take up COVID-19 vaccines (Head, 2016). Effective communication strategies in Australia give empirical evidence of good tidings including, but not limited to public trust, confidence, and behavior conformity (Siergrist \& Zingg, 2014). Similar sentiments have been captured by Hyland et al (2021) who see government communication to enlist and the cooperation of all stakeholders.

Government communication needs to give a clear balance on the issues that cloud COVID-19 vaccine uptake. There are diverse interests, needs and concerns. Significantly, Kenyans must consider multiplicity of information sources as they seek to change behavior. Social media continues to percolate information that needs to be moderated by having government provide information and take advantage of this channel to communicate facts. Technological disruption has its benefits, yet we cannot rule out the proliferation of misinformation.

Variant voices exist when adequate and correct information is not communicated. The different voices seem to be calling for clarification as the voices are muzzling the quest to take up COVID-19 vaccine. Several concerns abound including: the safety and effectiveness of vaccines; whether the vaccines have passed the rigorous tests and approvals; what benefits are accrued by those taking up the vaccines; why we need to mask up if we have taken the vaccines; how does the virus spread; how severe is the virus as other social problems have devastating results than has COVID-19; do the vaccines work to clear all the COVID-19 variants; and are we not playing along to the medical economic model meant to profit business magnets? All these situations need answers or else mistrust would get to higher levels. The line between the desired future and the reluctance to take up COVID-19 vaccine seems to be a communication gap.

Vaccine confidence is built when messages target and respond to the many fears associated with vaccine uptake. For instance, Habersaat and Jackson (2020) speak to some of the fears associated with the vaccine: what is the safety of the vaccines? Whether or not the vaccine exists; do the young people need it? Do COVID-19 survivors need the vaccines? What are the real side effects of the COVID-19 and are they severe than COVID-19 itself? When is the oral options being rolled out for this helps those who fear having an injection? Similar considerations have been advanced by Golden (2021). Government communication strategies should aim at correcting behavior and allowing an increased vaccine uptake.

Several things could be done including focusing on the endorsement and uptake of the vaccine by health workers. Endorsement from health workers speaks volumes in rallying patients and the public in general to take up the vaccines. Clear information, response to the many things that clutter uptake as well as public endorsement of vaccines by health workers - all serve to increase vaccine confidence levels and thereby reduce vaccine hesitancy. It is important that the strategies show that the vaccine has been recommended and the processes and polices have been followed from trials to the safety of the vaccines, licensure, and accentuated manufacturing. In taking a risk component of government communication, Habersaat and Jackson (2020) portent that the strategies should aim to affirming the following: (a) understanding the risks associated with vaccine take up; (b) understanding the beliefs associated with vaccines; (c) directing the public where they can get accurate, trustworthy, and up to date information on risks and benefits of COVID-19 vaccines; and co-relating and co-locating information on COVID-19 vaccine uptake relative to personal, cultural, and religious contexts.

\subsection{Research problem}

COVID-19 pandemic continues to wreak havoc among many families. Many people have lost their jobs, lost loved ones, and continued to stare at a very uncertain future. With infection rates in Kenya having hit a high of $18 \%$ in the recent past, it makes sense when medical experts indicate that the long-term solution to COVID-19 pandemic is herd immunity. 
Herd immunity is attainable when over $80 \%$ of the population is vaccinated. Kenya, like most countries, thus heavily relies on mass vaccinations. About 2 million people have either received two jabs or awaiting the second jab. Government communication on the uptake, safety and efficacy of the vaccines has been called out. While government continues to use different strategies to communicate on vaccine uptake, misinformation and conspiracy theories largely explaining the hesitancy. The worrisome nature of uptake seems to be propelled by doubts, fear, and miscommunication. If the strategies used by government are not addressed, the government efforts to urge vaccine uptake will go to naught and the country is likely to be in a devastating state as the spread and mutation of the virus continues. While there is an appreciation of constraining factors such as vaccine nationality 'wars', production constraints and stockpiling, vaccines seem to be the signature solution to COVID-19 malady, yet the uptake is notoriously disturbing, the situation can be problematized as a government communication issue. Government has a duty to communicate to citizenry on matters that improve citizens wellbeing and disregarding vaccine uptake maybe a ticking bomb to the country. This study sought to establish what drives the hesitancy and reluctancy in vaccine uptake by exploring the perceptions of COVID-19 survivors on whether the communication strategies utilized by government to urge Kenyans to get vaccinated reinforced the low vaccine uptake.

\subsection{Research questions}

This study was guided by the following research questions:

1. What strategies have been used by the Kenya government to communicate on COVID-19 vaccine uptake?

2. How have government communication strategies increased COVID-19 vaccine uptake?

3. What problems and prospects exist in government communication strategies on COVID-19 vaccine uptake?

4. What are citizens' perceptions towards government communication strategies on COVID-19 vaccine update?

\section{THEORETICAL FRAMEWORK}

The study was guided by the constructs of the Social Influence theory. The theory seats in the larger micro-interactionist tradition - which is the meta theory that focuses on the individual as one who can make decisions that help improve the society. The social influence theory was first advanced by Herbert Kelman. In more recent times, the theory has found an advocate in Robert B. Cialdini.

The theory postulates that an individual looks at the demands of a social environment and changes behavior. Put differently, the theory suggests that the social environment piles demand that seek to influence the attitudes, beliefs, perceptions, or behavior. In this sense, those with social influence either use explicit or implicit expectations. Explicit expectations are formally spelt out and are enforceable because of the existence of a senior (say government of any authority). On the other hand, implicit expectations are in the form of unwritten roles.

Three constructs in this theory remained a good model for this study viz., conformity, compliance, and obedience. Conformity has to do with real or imagined pressure that then demands a requisite behavior change. To check on how compliance played a role in COVID-19 vaccine uptake or hesitancy, I sought to understand why people say yes to the vaccine uptake initiative. Several factors influence compliance including scarcity, legitimacy, or authority (or avoiding the fallacy of argumentum ad verecundiam), peers, liking, commitment, and ignorance (avoidance of argumentum ad ignorantium). Obedience demands a change in behavior subject to the orders occasioned by the government. Citizens are obligated to obey the authority (Aswani, 2003) and works well when the subjects are given commands in general or have that people have no time, capacity, and willingness to interrogate the orders.

I simultaneously found the model presented by Habersaat and Jackson (2020) apt for this study. For Habersaat and Jackson (2020), vaccine uptake is a factor of capability, motivation, and opportunity. Capacity deals with individual's knowledge, skills and will power. Motivation is concerned with the individual's attitude, confidence, perceptions, trust, and value systems. Opportunity speaks of the context that the individual finds themselves in. The context has physical considerations such as accessibility, affordability, the laws and regulations, and convenience. The social aspects of context speak on the societal role in the form of cultural and religious inclinations that would offer cultural (or social) demands as well as social support. An interplay of the three is required to gain vaccine confidence and thus thrust the numbers to herd immunity.

\section{LITERATURE REVIEW}

Government communication is the management of relationships between the governors and the governed. We can further define government communication as the "constant exchanges of information and communication about policies, ideas and decisions between the governors and the governed" (Canel \& Sanders, 2012, p. 85). At a basic level, government communication is the communication from government officials to citizens on government policies, procedures, safety, 
and efforts to ensure security (Fairbanks, Plowman \& Rawlins, 2007). In postulating the different models in public relations, Grunig and Hunt (1984) classified government communication under the informational model which is focused on persuasion and hardly receives feedback from the public. This postulation has been confirmed by Mbeke (2009) who debunked the posture taken by the Kenya government that purports to be perfect in its communication. Mutere (1988) argues that the informational model was the logical answer to the quest by the Kenya government to focus on development. The citizens needed developmental information and hence the one-way communication model.

Kenya has gone through many developmental and technological disruptions. These disruptions created an environment that demands two-way symmetrical communication from government. The quest to have a two-way symmetrical communication model demands a focus on the needs, interest, and concerns of the multifaceted audience. Government communication is thus complicated output that considers the needs, interest, and concerns of the multifaceted audience; the complex governmental structure that includes the ministries, departments, and agencies in the three arms of government; and the mix of communication fields that play in the structure including risk, health, corporate, crisis, public, and corporate communication. The complexity in government communication demands the adoption of versatile strategies that ensure that the message is well received, and the desired action is taken. The government's communication policy is pegged on the understanding that Kenya has a knowledge-based population which requires their information needs satiated (GoK, 2015). This is a departure from the yesteryears where government communication was one directional (GoK, 2014).

In March 2020, Kenya reported its first case of Corona virus and with that the government engaged in several strategies that would help communicate with citizens. The ministry of health officials became the focal point for dissemination of the information. On several occasions, the president gave presidential updates that contained guidelines and measures taken by the government to contain the spread of the virus.

The arrival of different vaccines in Kenya was received with mixed feelings. While some citizens were happy that this would be a solution to the many problematic effects of the virus, others felt that it was so soon to discuss vaccine uptake given the vast questions that remained unanswered. On its part, the government continued to communicate daily on the statistics of those infected, healed, dead, and vaccinated.

The government officials took it as their constitutional duty to inform the public what was happening. The Constitution, in articles 20,33(1), and 34, obligates government to respond to the informational quests that Kenyans have. Specifically, article 35 (3) obligates the state to publish and publicize any information deemed important and likely to affect the nation. One can classify information on COVID-19 as one that has affected the nation. In addition to the constitution, other legal and policy instruments factored in the communication on COVID-19 19 include Access to Information Act, 2016; Kenya Information and Communication Act, 1998; Media Council Act, 2013; Copyright Act, 2001; Oath of Secrecy Act; Public Service Commission Act, 2017; Public Officers Ethics Act, 2003; Civil Servants Code of Conduct, 2007; Public Sector Communications Policy, 2015; Security Laws (Amendment) Act, 2014; and Kenya's Vision 2030. The Government of Kenya's communication policy expects the government to speak in one voice, capitalizing on the fact that communication is the glue that holds together all the government units. The policy focuses on strategies available to government communicators including use of traditional media (electronic and print media) and social media (GoK, 2015).

While it is appreciated that messages on COVID-19 are unfolding with time, it is possible that some things remain uncertain. Yet even with uncertainty, audiences need information communicated with clarity. Studies focusing on vaccine hesitancy in medical history and risk communication suggest that uncertainty would propel hesitancy (Fischhoff, 1995; Heath \& Gay, 1997; Fischhoff \& Kadvany, 2011). For COVID-19 vaccines, different strategies have been suggested including: the endorsement by health personnel (Leask, Kinnersley, Jackson, Cheater, Bedfords \& Rowles, 2020); dialoging with the grassroots; and going beyond statistics (Awobamise, Jarrar, \& Okiyi, 2021). I found Hyland-Wood, Gardner, Leask, and Ecker's (2021) such a relevant prescriptive study with a myriad of suggested strategies that need some empirical gauge. Some of the strategies suggested are clear communication; striving for maximum credibility; communicating with empathy; communicating with openness, frankness, and honesty; recognizing uncertainty; account for levels of health literacy and numeracy; and empowering people to act; appealing to social norms; combating misinformation; and considering diverse community needs.

\section{METHODOLOGY}

Seated in the constructivist paradigm, this study considered the reality of many participants on perspectives that people have towards government communication strategies on COVID-19. Multiple reality within the constructivist tradition is underpinned by the fact that individual's subjective experiences of their external world are considered by other individuals in the same space to socially contrast perspectives.

Intersubjective convergence of experiences and thereby the resultant reality, depends on how people interact with one another. In this study, I was interested in the "complexity of views rather than narrow the meanings into a few categories or ideas" (Creswell, 2013, p. 24). Within the paradigm, I took a hermeneutic phenomenological design which helped me focus on essences (Moustakas, 1994, van Manen, 2016). Drawing from the works of Martin Heidegger, the design helped utilize the rich descriptions from participants and tap into participant primordial consciousness on COVID-19 government 
communication strategies (Crotty, 2015, p. 96).

Phenomenological studies focus on small samples with hermeneutic phenomenological studies looking at ten participants. In the study, I carried out 10 intense interviews. The ten participants were sampled since they had faced the reality of COVID-19 medical effects and had either taken the vaccines or had opted not to. Data explication meant that I theme out the perceptions of participants in the form of perspectives, problems and prospects identified in the strategies used by government to communicate on COVID-19 and thus spur vaccine uptake. Pseudonyms are used to protect the identity of the participants and thus allow me to anonymize my study by sharing a socially constructed reality.

\section{FINDINGS}

In this study, it emerged that there was great potential in government communication strategies in rallying populations for COVID-19 vaccines. Data explicated shows the government has engaged the right strategies, but the message does not seem to trigger the right attitudes among Kenyans given that their unanswered questions remain as such. Rather than striking the notes and missing the music, the message from government should seek to align to the needs, interests, and concerns of the populations. The findings are presented in the subsequent sub-sections.

\subsection{Communication strategies}

Participants in the study referred to some of the communication strategies used by the government to rally Kenyans to take up the COVID-19 vaccine. The discussions hereunder speak to the strategies themed out when the question was posed to participants on ways the government was communicating on the COVID-19 vaccination process:

\section{Availing daily statistics on COVID-19 pandemic and vaccinations}

Government of Kenya has dutifully given a daily briefing on the COVID-19 situation and by extension statistics on vaccination. Participant Cvv6 captured it aptly when he told me:

The government took the strategy of briefing the nation on what was happening. Since the first case was reported last year, we have been received communication from Ministry of Health daily. We are informed of the numbers of those infected, how many have died, the numbers in ICU and HDU. A similar trend was followed when we started receiving vaccines. Daily we are told of the numbers that have received the first dose or fully vaccinated. At times the details are broken down to counties and areas of focus.

This strategy was later depicted as the basic of the strategies used by government. Thematic reflections from participant narrations show the angst among participants. More is required beyond the statistics shared by the government.

\section{Leading by example}

While studies seem to link the endorsement of medical workers with an increase in vaccine uptake (Habersaat \& Jackson, 2020), this study established that in leading by example, government officials helped some of the participants take up the vaccine. For instance, participant $\mathrm{Cvv} 4$ noted that the vaccine uptake increased when government officials took their vaccines publicly. In her assessment, unverified information propelled hesitancy among the general population until the public vaccination of government officials led by the president served as the icebreaker. From her interview, I delineated a tonality that much as the public vaccination served as an endorsement, the public treated the entire event as a guinea pig. When the public saw them go about their normal activities after the inoculation, they got the cue that all was well and that the vaccines were safe after all. In her words, participant Cvv4 noted: when we saw the president, first lady, cabinet secretaries, and a host of other senior government officials publicly take their vaccines; we were encouraged to take up the vaccines. The public display helped endorse the vaccination project. You saw the numbers went up immediately. It is not in Kenya alone. It happened in Uganda, Tanzania, and many other countries. Her sentiments were echoed by participant Cvv8 who confirmed that it was the public endorsement of the vaccination that helped her decide to take the COVID-19 vaccine. Government communication makes sense when the strategies demonstrate that government has actioned what it communicates (Aswani, 2021).

\section{Throwing weight behind subject matter experts' sentiments}

Messages from public servants in the medical and scientific fields helped government reinforce its ask of Kenyans to take up COVID-19 vaccines. Participants noted that it was believable when doctors and medical experts spoke on the safety of the vaccines. Experts' endorsement of what the government was saying helped remove the doubt on the veracity of 
government messages. Each time a medical doctor or a public health official would field questions in media, the government would take that as a government position. Government decisions were equally backed up by arguments by the experts as well as their physical presence. In a sense, the government was telling the public that our message is fortified by science and that experts cannot go wrong. Participant Cvv1 captured this strategy well when he argued:

Government has been rallying medics to affirm some of the decisions it makes. I remember when the country felt that the curfews were not effective, the president built his arguments around saving lives versus saving livelihoods. He seemed to be sympathetic to the pain points of Kenyans, but he chose saving lives. He alluded his decision to the strong advice he received from different experts in medical and scientific fields. That day, I remember the experts accompanied him as he read the executive order.

\section{Using social, political, and religious influencers}

A mix of government and non-government actors were enlisted as part of the government strategies to communicate on COVID-19 vaccination. Participants Cvv2 and Cvv6 noted that government rode on the sentiments of social, political, and religious influencers. This strategy aimed at utilizing the influencer's sphere to pass the message on vaccine uptake. Participant Cvv6 remembered what happened when the Kenya's former premier Raila Odinga informed the country that he was battling COVID 19. Everyone followed what transpired and government rode on the former PM's endorsement of inoculation. With such a huge political base, the endorsement by the former premier meant that good number of his supporters would follow suit. Participant Cvv2 mentioned the events leading to Bishop Muheria's endorsement of vaccine. Being the chair of the Interfaith Council that works with government to ensure that religious groupings follow the laid down protocols, his endorsement soon after surviving the COVID 19 attack meant that congregants would take his endorsement seriously. The same trend has been followed each time an influential person in the social, political, and religious fraternity has endorsed inoculation. Participant accounts showed that the message of influencers only made sense when they were recovering or had recovered from COVID 19 complications. An influencer's endorsement carries much weight.

\section{Adopting sympathetic and empathetic posture in messaging}

Participants found it so compelling that government officials identified and sympathized with those having been through the different issues around COVID-19. It was clear that the government had taken a posture that sympathized with Kenyans given their circumstances. Similarly, government empathized with those going through the challenging COVID-19 season. Participant Cvv4 told me that the fact that medical workers and other frontline workers together with the aged were singled out as the possible first beneficiaries of the vaccine, the government was taking a very empathetic posture. It has been argued that a society or a government will have its values revealed by the priorities it sets in the face of risks. In fact, a country is known by how much it manages risks (Fischhoff \& Kadvany, 2016). Akin to participant Cvv4's comments, participant Cvv2 told me:

Although the passion initially seen among Ministry of Health officials when they communicated about COVID-19 had waned, we still see traces of a sympathetic government that wants what is good for the population. We see an empathetic push to people to get vaccinated and such messages are communicated relative to the disturbing trends of those losing lives.

The government seems to be taking the position that government is all things to all people so that by all possible means, the government can have as many people get vaccinated. This strategy shows the soft approach taken by government and which is contrary to the often assumed incommunicado, inaction oriented and largely fluid communication strategy that hardly guides citizens on what decisions they need to take (Aswani, 2020). It would follow that government communication strategies are likely to change as countries confront different issues. In communicating during the COVID 19 pandemic season, governments are likely to take a humane approach since the pandemic threatens the very citizens who comprise what is the country. Further, where the country is facing challenges that can affect the governors and the governed, the approach to communication is likely to take a sympathetic and/or empathetic posture.

\section{Scaling down the medical jargon and statistics}

Citizens can get tired, even frustrated, when government throws around statistical information. As the enthusiasm among Kenyans waned around the daily statics, government officials took the strategy of breaking the information in the most basic manner. Put differently, the government adopted the strategy of bringing information closer to the people and demystify the clouded statistical and medical information. Participant Cvv1 noted: 


\begin{abstract}
I have been keen to notice that people got tired with the numbers that the Ministry of Health officials were pushing each passing day. The strategy changed in that we noticed officials make deliberate efforts to breakdown numbers and relate the situation in our terms. Concepts such as quarantine and isolation have been appropriated to simplified terms. The composition of vaccines and the heavy medical jargon have been made easier. Today, I can relate with what happens in the vaccination campaign without straining my mind. I talk to my friends, and you get a similar feeling. Ordinary people can now have a meaningful conversation about COVID-19 and vaccine uptake without referring to the agonizing medical terms and vocabularies.
\end{abstract}

Repackaging statistical information to relatable levels is a good strategy to reach many people. This strategy can work well if the relatable qualities also speak to the other concerns that citizens have. Clarity in communication is good, but clarity on issues addressed only makes sense when the current uncertainties are addressed. In other words, being clear demands an honest conversation about the uncertainties faced on an issue (Fischhoff, 1995). Fischhoff and Kadvany (2016) argue that risk management demands that organizations and societies rally a pool of experts who may help communicate the relevant uncertain facts that face the society and the risks they pose.

\title{
7. Relying on print and electronic media to pass government messages
}

Participant accounts revealed that government had heavily relied on the traditional media - wherein electronic and print media had been used to pass government messages. In this sense, government was showjumping on the coverage and hoped that the fact that citizens rely on these media, the message would easily get home. Participant Cvv10 mentioned that government also employed strategies such as use of public address system and placing posters informing Kenyans on areas where Kenyans can secure the vaccines. The public address systems were also used to rally people in their areas of residence to visit the health centers where the inoculators were visiting. Participant Cvv10 was worried that even this strategy did not speak to the uncertainties that confronted her.

\section{Compelling messages}

The government put in place measures to increase the vaccine uptake among vulnerable groups. One of the targeted groups was that of public servants. Having considered the low uptake among the public servants, the government had resorted to a compelling strategy where no uptake of COVID-19 vaccine will be treated as a case of indiscipline. In the circular, the head of Civil Service gave public servants till 24 August 2021 to have taken the jab. This directive shocked some participants as was expressed by participant $\mathrm{Cvv} 9$ who wondered why the government was compelling people to take the vaccines. She wondered how government could be tough on its own officials. She painted the dilemma that civil servants had been subjected to by government arguing that I am often puzzled by the way government does things... First, you tell them to work from home, they you insinuate they cannot work from home since they have no infrastructure to support this. For participant $\mathrm{Cvv9}$, civil servants too, had uncertainties that needed to be addressed. If these concerns were not addressed, the levels of hesitancy among the rank and file would remain high. Her sentiments however differed from those of participant Cvv5 who though appreciating that force was used, he saw the need to have everyone vaccinated. His narration went:

I have seen the fuss around the letter asking civil servants to be vaccinated. We need to decide what we really want. Civil servants, by virtue of their job will serve so many Kenyans. In their interactions, they may spread or receive the virus. Like all sectors in the society, a good number of civil servants have succumbed to COVID-19. It will be wrong to allow many more to die. It will be atrocious to let civil servants spread the disease. While government allowed people to manage the disruptions, civil servants needed to be armed and ready for the work they need to do - serving Kenyans. I honestly see no issue in compelling civil servants to take this jab.

Eniola (2021) gives four reasons why there is hesitancy among healthcare workers (HCWs) key among the reasons is distrust in what government and health organizations tells the public. HCWs are not spared from conspiracy theories which lead to doubts regarding the spread, prevention, lethality, and vaccine safety. Eniola guesstimates that HCWs will benefit from accurate information from credible sources placed on social media which carries a chunk of distorted information. For government to compel public servants, it means that the right strategies had not been engaged, yet the public depends on HCWs to firm up their vaccine confidence. Hesitancy among HCWs means to hesitancy in the general population. In our context, if civil servants do not trust the messages coming from the central government, then there is every reason for their families and the public to shy away from vaccination. This strategy is the weakest link as it fortifies the unwillingness to take up vaccines. 


\subsection{Perceptions towards government communication strategies: Problems, prospects, and perspectives}

\subsubsection{Problems}

\section{Communication without meaningful information}

The study findings revealed problems associated with the communication strategies used by government. It emerged that messages from the government lacked the requisite information. The infodemic penetration was reducing the levels of vaccine confidence, yet government communication is not putting facts straights. Participant Cvv10 told me that:

It is true that government has even come close to me. I heard through the public address system that the medical team was in my neighborhood administering the vaccine. That was good enough information. I did not hear what they said in response to information we receive on social media. We are told that the vaccine interferes with the reproductive organs. Further, we are told that in two years, those who take the vaccine will die. I mean who wants to save their life and die in two years? Hence, the government is talking but I cannot hear them addressing the thoughtful concerns that makes me reluctant to get vaccinated.

Messages were not fully understood. Perhaps the speculations of John Locke on language are handy. It was Locke's thesis that philosophical underpinning of communication demands that man remains the 'master of meaning' capable of making "common understanding between individuals, both desperately urgent and highly problematic" (Peters, 2013, p. 389). In tracing a connection between language and meaning, Locke saw every opportunity of having what is communicated to be relayed to the receiver (Locke, 1979). In the second chapter of Locke's Third Essay, we read: "When one man speaks to another, it is to be understood; and the goal of his speech is for those sounds to mark his ideas and so make them known to the hearer. What words are marks of, then, are the ideas of the speaker." (Locke, 1979, p. 146). Participant accounts indicated that government communication strategies led to messages without meaning.

Participants felt that communication strategies should spur trust in government messages. To do this, government needs to speak to the interests, needs, and concerns of citizens. Communication strategies used by government should counter the conspiracy theories. When government is incommunicado or speaks partial truths, then such a sterile environment gives rise to conspiracy theories (Lewandowsky \& Cook, 2020). When people lack the necessary information, they consider themselves victims and are likely to seek avenues where they can be heard. Social media becomes one of the avenues and such victim hyphenated citizens find pleasure and solace in advancing their thoughts about the vaccines. Government needs to tap into the social media space that seems to have unlimited space, unlimited audience, and apparently no gatekeepers. In the context of Locke's argumentation, Kenyans need COVID 19 vaccines, but they cannot secure mental picture far removed from the words of the government - pictures that relay the reality and severity of the pandemic. This speaks to the lack of, or failure of the strategies currently used.

\section{Which way for government}

The second problem explicated spoke to the clash of communication strategies used by government. From the accounts of participants, the way government was handling places of worship and social places such as bars spoke to a confusing strategy. For instance, religious organizations were to operate on one third of their sitting capacity. Social places such as bars have no space restrictions and as such participants such as Cvv6 observed that whereas social places were allowed to operate in an uncontrolled manner, the government now seeks religious institutions to partner with it to roll out vaccinations. It defeats reason, why government would allow potentially super spreaders to thrive then delimit avenues that promote an ambience of safety. Participants Cvv6 painted a picture of a distraught citizen who wondered why government would not vaccinate people in bars and instead seek the churches and mosques for partnership.

Another avenue of clash of communication strategies was captured in the interview with participant Cvv1. For the participant, whenever subject matter experts were in a discussion, they could not agree on mundane issues. While government was depending on the experts to authenticate agreed medical strategies, the fact that they could not agree on basics lead to hesitancy. Participant Cvv1 picked from news items that the uptake of COVID 19 vaccine among medics was worrisome. The reluctancy among medics to take up could partly explain the reluctancy among the public. In his words, participant Cvv1 wondered:

Why would I be urged to take the vaccine, yet those with the wherewithal are reluctant to take the vaccine. You can see the contradiction: that those who know about vaccines, have knowledge and perhaps the required resources fear taking the vaccines, yet [the medics] urge the ordinary citizen to take the vaccine. 


\subsubsection{Prospects}

\section{The unharnessed giant}

As far as prospects are concerned, the study findings showed the need to harness the untapped potency in the use of social media. Proper use of social media can reduce infodemic driven hesitancy. Giving information to the different audiences on vaccine uptake was not sufficient. There is need to address the concerns raised on social media that could be driving down the numbers taking up the vaccine. More specifically, participant Cvv3 gave her view of the government's presence on social media. In her words:

The Ministry of Health has been on Facebook and twitter. I do not know much about Instagram, but I can tell you that the ministry has been pumping information on COVID-19. We can get the same statistics on the website. What I do not like is that the strategy by government seems one that gives numbers and numbers. I have not seen any concerns being addressed. When I got my injection, it was because of people away from government. Imagine my circles had questions on the safety of the vaccines and no one got answers. I belong to a group that discusses the side effects of COVID-19 vaccines. People speak about changes in their reproductive system. Cases of miscarriage are discussed. People have painful menstrual cycles. While I went for my vaccine because I feared getting COVID-19, my resolve was strengthened not by government messages or strategies. I was assisted in making the decision because my space had people who had lost loved ones to COVID-19. In a nutshell, government has taken the strategy of communicating through social media for purposes of giving information. Government loves giving information. I wonder who is expected to make sense of the information.

\section{Continually engage stakeholders}

The second prospect themed out of the finding was the need for government to continually engage different stakeholders and thus allow government and non-government actors to speak to the fears associated with COVID-19 vaccines. Participant Cvv7 helped show the complexities with the way government works. Previous pandemics have seen government rally citizens based on the different interests. Government needed to come up with different communities based on their needs, interests, and concerns. On COVID-19, several communities have been created including the youth, the aged, professionals, religious loyalists, and traditionalists among others. All these communities need to be engaged in a continuous manner. They have fears that need to be addressed. As it now, the communities have been left on their own. In fact, participant Cvv7 told me that the everyone seems to be on their own.

\section{Incentivize citizens through government support}

The third prospect spoke to the support received from government. This was termed the ultimate strategy for it spoke on how government could partner with citizens and together push the numbers taking up the vaccine. It was generally perceived that the tax incentives given by the government in 2020, showed the empathy that government had for citizens. When the government vacated the decision to incentivize citizens, citizens felt they had been thrown under the bus. I found the thoughts of participant Cvv8 apt to explicate the prospect:

On the onset of the COVID-19 in the country, the government made a historic move that incentivized citizens by reducing taxes and allowing companies and business to support Kenyans. This was so encouraging and if the incentives were juxtaposed with vaccine uptake, then Kenyans would have gone for vaccines. In fact, we would be talking about vaccines scarcity and not hesitancy. Instead of riding on this empathy, the government removed the incentives as though COVID-19 was over. Assuming that the supposition is true, why would the government ask our hand of support in taking up vaccine, yet they pushed citizens into believing that things went back to normalcy? For me, incentivize the citizen and you get their unwavering support.

\subsubsection{Perspectives}

\section{Blurred communication}

Participant accounts showed that government communication was not clear. There was need to address the fears around vaccines and vaccines uptake. It would follow that government communication strategies did not bring audiences to the much-needed trust. The communication strategies did not show the government as credible. Clarity is central to communication (Kaul, 2009) for it would show an open government communication policy and strategy that would onboard and endear audiences. Instead of communicating clearly, it was the perspective of some participants that government had a pompous attitude as it communicated. Some of the strategies used by government were showoff. Participant Cvv4 perhaps captured this well: 
Why has the focus on vaccine uptake been a conversation focusing on the well to do? What explains that we are told the situation is so bad, yet political meetings continue? When government officials are asked to explain the anomaly, they often tell us to focus our energies on safeguarding ourselves and leave the political class alone. This arrogant character is making the campaign on COVID-19 vaccine usage a mirage. They should focus on politicians first then come to the ordinary citizen.

\section{Contradictory communication}

Further, when participants talked about clash of strategies, there is a perception that government gives contradictory information. Government cannot say something in one way and seem to negate the same information through a different strategy. Participant Cvv10 told me:

Let me tell you. We see in other countries the use of one vaccine is preferred to another. In Kenya, the less effective vaccine is taken unquestioned. Then we are told there are studies supporting the combination of different vaccines... what we call Kitenge in Kenya in reference to many colors on one cloth. The mixture of vaccines has taken different positions among government officials. First it was a no-no. We then moved to it can be used. I wonder what government knows about this or what its position on booster vaccines is.

\section{Transparency and coordinated communication}

Citizens expect transparent and coordinated communication (Aswani, 2020b). Whenever an issue threatens the lives of citizens, citizens expect government to speak in one voice and discharge its duty in a coordinated manner. Participant Cvv4 thought government had done well. For him, government had coordinated messaging. In having the Ministry of Health coordinate communication helped address many concerns. The Ministry's website has information populated in real time.

Participant Cvv5 gave a critical appraisal of the coordination of government communication strategies. It can be observed that having a centralized command center served to give coordinated information but that is not a sufficient strategy if it does not win the support of publics. Participant Cvv5 told me:

I love it that government allowed the ministry of health to run with this. The ministry of health has coordinated COVID-19 information in an amazing way. Having said this, I find fault in the way the strategy runs beyond the coordination. When we had the census, government came up with a robust strategy and a slogan. It was easy to identity the presence and place of the citizen in the entire process. It was so easy to then tell other people that one had been vaccinated. The COVID-19 strategy is neither here nor there. I find government trying to do everything at the same time. Citizens have not been rallied and they feel left out. What would one expect than that people are reluctant to take the vaccine?

Some of perspectives praised the strategies utilized by the government to ask Kenyans to increase their vaccine uptake. Whereas perspectives showed blurred and contradictory communication in the strategies used by government, there has been positive perspectives on how coordinated communication has been on COVID-19. There is need to coordinate the strategies from one center and possibly, push similar coordination in the communication that urges Kenyans to take up the different COVID vaccines available in the country.

\section{CONCLUSIONS}

The discussions above point to the fact that intentions are not good enough. Implementing strategy would actualize the intentions and thus make it easy for the need (in this case vaccine uptake) to be met. While the government has very clear communication strategies, the very things that keep people away from the vaccine seem to be neglected whenever government communicates. There is need for government to meet the patients and public's communication needs and narrow the gaps that promote hesitancy. Incorporating risk in government communication means a conscientious effort to eliminate uncertainty. When people have even an iota of doubt when it comes to COVID-19 vaccine uptake, the country is in the realm of hesitancy. Government communication strategies should strive to answer all the concerns around COVID19 and COVID-19 vaccines to create an anecdote to infodemic. The participants who have taken up vaccine are those who have seen firsthand the effects of COVID-19 and wished not to be in a similar situation. Government communicators need to engage in persuasive strategies that would appeal to Kenyans. This is the sure way to increase vaccine confidence and attain desirable levels of herd immunity.

\section{REFERENCES}

[1] Aswani, D. R. (2003). Technocracy and political obligation. (Unpublished MA Dissertation) University of Nairobi. 
[2] Aswani, D. R. (2021). Victims' perceptions towards government communication on terror: A case of Garissa University College terror attack. (Unpublished Doctoral Dissertation) Daystar University.

[3] Aswani, D. R., Mbutu, P., \& Mwithia, K (2020a). Exploring Terror Victims' Expectations of Government Communication. International Journal of Media, Journalism and Mass Communications (IJMJMC), 6(4), 7-19. https://doi.org/10.20431/2454-9479.0604002

[4] Aswani, D. R., Mbutu, P., \& Mwithia, K. (2020b). Victims understanding of government through actions and communication: The case of Garissa University College terror attack. International Journal of International Relations, Media and Mass Communication Studies, 6 (3), 1-13.

[5] Awobamise, A. O., Jarrar, Y., \& Okiyi, G. (2021). Evaluation of the Ugandan Government's Communication Strategies of the COVID-19 Pandemic. Online Journal of Communication and Media Technologies, 11(1), e2021xx. https://doi.org/10.30935/ojcmt/10824

[6] Canel, M. J., \& Sanders, K. (2012). Government communication: An emerging field in political communication research. In H. Semetko \& M. Scammell (Eds.), The Sage handbook of political communication (pp. 85-96). London, UK: Sage.

[7] Creswell, J. W. (2013). Qualitative inquiry and research design: Choosing among five approaches (3rd ed.). Thousand Oaks, CA: Sage.

[8] Crotty, M. (2015). The foundations of social research: Meaning and perspectives in the research process. Thousand Oaks, CA: Sage.

[9] Dalzell, S. (2020). Government Warned of Coronavirus "Missed Opportunity" to Protect Migrant Communities before Victorian Spike, ABC News (online, 24 June 2020). Available at https://www.abc.net.au/news/2020-06-24/governmentwarned-failing-engage-migrant-communities-coronavirus/12384800

[10] Eniola, K. (2021). Four reasons for COVID-19 vaccine hesitancy and health care workers, and ways to counter them. Available at FPM (aafp.org).

[11] Fairbanks, J., Plowman, K. D., \& Rawlins, B. L. (2007). Transparency in government communication. Journal of Public Affairs: An International Journal, 7(1), 23-37.

[12] Fischhoff, B. (1995). Risk perception and communication unplugged: twenty years of process 1. Risk analysis, 15(2), $137-145$.

[13] Fischhoff, B., \& Kadvany, J. (2011). Risk: A very short introduction. Oxford, UK: Oxford University.

Golden, S.H. (2021). COVID-19 vaccine hesitancy: 12 things you need to know. Available on www. https://www.hopkinsmedicine.org/

[14] Government of Kenya. (2013). Organization of the Government of the Republic of Kenya (Executive Order No. 1/2013). Nairobi, Kenya: Government Printer.

[15] Government of Kenya. (2015). Public sector communications policy. Nairobi, Kenya: Government Printer.

[16] Grunig, J. E., \& Hunt, T. T. (1984). Managing public relations. New York, NY: Holt, Rinehart and Winston.

[17] Habersaat, K. B., \& Jackson, C. (2020). Understanding vaccine acceptance and demand-and ways to increase them. Bundesgesundheitsblatt-Gesundheitsforschung-Gesundheitsschutz, 63(1), 32-39.

[18] Head, B. W. (2016). Toward more "evidence-informed" policy making? Public Administration Review, 76(3), 472484.

[19] Heath, R. L., \& Gay, C. D. (1997). Risk communication: Involvement, uncertainty, and control's effect on information scanning and monitoring by expert stakeholders. Management Communication Quarterly, 10(3), 342-372.

[20] Hyland-Wood, B., Gardner, J., Leask, J., \& Ecker, U. K. (2021). Toward effective government communication strategies in the era of COVID-19. Humanities and Social Sciences Communications, 8(1), 1-11.

[21] Kaul, A. (2009). Business Communication. PHI Learning Pvt. Ltd.

[22] Leask, J., Kinnersley, P., Jackson, C., Cheater, F., Bedford, H., \& Rowles, G. (2012). Communicating with parents about vaccination: a framework for health professionals. BMC pediatrics, 12(1), 1-11.

[23] Lewandowsky, S., \& Cook, J. (2020). The Conspiracy Theory Handbook. Available at http://sks.to/conspiracy

[24] Locke, J. (1979). An essay concerning human understanding. Oxford, UK: Clarendon.

[25] Martin, A., Gravelle, T. B., Baekkeskov, E., Lewis, J., \& Kashima, Y. (2019). Enlisting the support of trusted sources to tackle policy problems: The case of antimicrobial resistance. PloS one, 14(3), e0212993. https://doi.org/10.1371/journal.pone.0212993

[26] Mbeke, P. O. (2009). Status of public relations in Kenya. In K. Sriramesh \& D. Vercic (Eds.), The global public relations handbook: Theory, research, and practice (2nd ed., pp. 370-393). Abingdon, UK: Routledge.

[27] Ministry of Health Kenya, 2021 COVID-19 Update. Available on the ministry website https://www.health.go.ke/COVID-19/

[28] Moustakas, C. (1994). Phenomenological research methods. Thousand Oaks, CA: Sage.

[29] Mutere, A. (1988). An analysis of communication policies in Kenya. Africa Media Review, 3(1), 46-63.

[30] National Council for Law Reporting. (2010). The Constitution of Kenya, 2010. Nairobi, Kenya: Author.

[31] Owakah, F. E. A., \& Aswani, R. D. (2009). Technocracy and Democracy: The Challenges to Development in Africa. Thought and Practice, 1(1), 87-99.

[32] Peters, J. D. (2013). Speaking into the air: A history of the idea of communication. Chicago, IL: University of Chicago. 
[33] Rzymski, P., Borkowski, L., Drąg, M., Flisiak, R., Jemielity, J., Krajewski, J., \& Fal, A. (2021). The strategies to support the COVID-19 vaccination with evidence-based communication and tackling misinformation. Vaccines, 9(2), 109, 1-9.

[34] Siegrist, M., \& Zingg, A. (2014). The role of public trust during pandemics: implications for Crisis communication. European Psychologist, 19(1):23-32.

[35] van Manen, M. (2016). Researching lived experience: Human science for an action sensitive pedagogy. Abingdon, UK: Routledge.

[36] van Der Bles, A. M., van der Linden, S., Freeman, A. L., \& Spiegelhalter, D. J. (2020). The effects of communicating uncertainty on public trust in facts and numbers. Proceedings of the National Academy of Sciences, 117(14), 7672-7683.

[37] Wynne, B. (2006). Public engagement as a means of restoring public trust in science-hitting the notes, but missing the music? Public Health Genomics, 9(3), 211-220. 